\title{
ATIVIDADES CIRCENSES COMO CONTEÚDO NAS AULAS DE EDUCAÇÃO FÍSICA: LIMITES E POSSIBILIDADES
}

\section{CIRCUS ACTIVITIES AS CONTENT IN PHYSICAL EDUCATION CLASSES: LIMITS AND POSSIBILITIES.}

Daniele Gonçalves Lisbôa Gross ${ }^{1}$, Anna Karoline Nogueira de Santana², Michele Aguiar de Lima Oliveira², Letícia Gama³ ${ }^{3}$, Wylker de Souza Saraiva ${ }^{4}$, Maisa Bruna de Morais Teixeira do Nascimento ${ }^{6}$, Iron Martins Lisbôa Júnior ${ }^{7}$ \begin{abstract}
menção às práticas inseridas na Educação Física Escolar, contudo o tema a ser trabalhado neste estudo são atividades circenses como conteúdo nas aulas de Educação Física. O objetivo do referido estudo foi, verificar os limites e possibilidades de inserção das atividades circenses como conteúdo nas aulas de Educação Física e como esse conteúdo tem sido trabalhado na proposta curricular de Gurupi-TO. Metodologicamente, trata-se de pesquisa de campo e documental, de natureza qualitativa e se desenvolveu a partir de uma perspectiva exploratória descritiva. Para a análise das informações obtidas a partir da entrevista semiestruturada, utilizou-se da técnica de análise de dados elaborada por Moreira, Simões e Porto (2006). Para análise documental foi utilizado na perspectiva de Bardin (2009). As atividades circenses em sua totalidade não se apresentam no documento referência. Todos os entrevistados confirmam já trabalhar com atividades circenses em suas aulas de Educação Física, porém, há falta de materiais e estrutura para tal prática. Contudo é possível perceber que as atividades circenses, no documento referência são percebidos nos conteúdos, como atividades rítmicas e expressivas ginástica, jogos e esportes. As principais limitações são, portanto, a falta de materiais e de espaço adequado. No que concerne às possibilidades pode-se afirmar que está no poder adaptar e estimular a criatividade nos alunos através das atividades circenses.
\end{abstract}

Palavras-chave: Atividades circenses. Educação Física Escolar. Proposta Curricular. Ensino Fundamental.

\section{ABSTRACT}

The circus activities are combined with movements from the corporal culture, and makes mention to the practices inserted in the contents of Physical School Education, based on this understanding the theme to be discussed in this study are circus activities as content in Physical Education classes. The main objective of this study was to verify the limits and possibilities of insertion of circus activities as content in the Physical Education classes and how this content has been worked on the curricular proposal of Gurupi-TO. Methodologically, this is a field and documentary research, of a qualitative nature and developed from a descriptive exploratory perspective For the analysis of the information obtained from the semi-structured interview, we used the data analysis technique developed by Moreira, Simões and Porto (2006), developed through three recommended phases, which are: naïve report, identification and interpretation of attitudes. For documentary analysis we used the technique of content analysis based on Bardin's (2009) perspective. The circus activities in their totality are not presented in the document, however it is possible to perceive the circus activities through contents such as rhythmic activities and expressive gymnastics, games, fights and sports. The main limitations are lack of materials and adequate space, and the possibilities are linked to being able to adapt and stimulate creativity in the students through circus activities.

Keywords: Circus activities. School Physical Education. Elementary School. Curricular Proposal.
${ }^{1}$ Prof 3 . Orientadora, Graduada em Educação Física, Licenciatura plena, pela Universidade de Gurupi - UnirG, Especialista em Educação Física Escolar.

E-mail: danielegross86@gmail.com ${ }^{2}$ Acadêmica do Curso de Educação

Física da Universidade de GurupiUnirG, Gurupi/TO.

${ }^{3}$ Graduada em Educação Física, licenciatura e bacharelado, pela Universidade Paulista, Campus Brasília, especialista em Educação Física Escolar, Atividade Física e Lazer.

${ }^{4}$ Graduado em Educação Física, licenciatura plena, pela

Universidade de Gurupi - UnirG, Especialista em Educação Física com ênfase em treinamento Esportivo.

${ }^{5}$ Graduada em Educação Física, Licenciatura, pela Universidade de Gurupi - UnirG

${ }^{6}$ Graduado em Educação Física, Licenciatura plena, pela Universidade de Gurupi - UnirG, Especialista em Educação Física Escolar. 


\section{INTRODUÇÄO}

As atividades circenses estão combinadas com movimentos da cultura corporal e faz menção às práticas inseridas nos conteúdos da Educação Física Escolar. Pode-se considerar que, quando praticadas por alunos em idade escolar, desenvolve aspectos pessoais como a cooperação, a sensibilidade na expressão corporal e a criatividade. "Por se tratar de uma atividade que traz grande fascínio e motivação para as crianças e por ser algo diferenciado do que se está acostumado a ver no âmbito escolar, pode ser mais um instrumento a ser aplicado na escola" (CARAMÊS et.al., 2012, p.180).

Importante ressaltar que as atividades circenses podem ser entendidas como conteúdo ou instrumento pedagógico a ser explorado nas aulas de Educação Física Escolar, já que tais atividades apresentam uma riqueza de possibilidades para a aprendizagem, não somente na parte afetiva, mas também nas discussões de valores que a englobam e no pleno desenvolvimento de suas habilidades motoras (CARAMÊS e SILVA, 2011).

Para Ferreira e Conceição (2013) as atividades circenses devem ser tratadas pedagogicamente pela Educação Física como um saber relativo à cultura corporal a ser trabalhado com os alunos, a fim de promover a compreensão e a valorização destas manifestações artísticas. Contudo, devem ser tratadas de forma lúdica no âmbito escolar, com o intuito de possibilitar ao aluno, a descoberta de suas possibilidades físicas e expressivas além dos valores educacionais fundamentais para a vida da sociedade. Todavia, nota-se a importância das atividades circenses enquanto parte significativa da manifestação cultura corporal.

Concomitantemente à presente discussão, este estudo apresenta as atividades circenses como conteúdo da Educação Física Escolar, com a proposta de expor os limites e possibilidades da inserção de tal conteúdo nessas aulas. Após várias intervenções, discussões, participação em oficinas, e leituras sobre o tema, interrogações surgiam a respeito de como esse conteúdo é tratado nos documentos que referenciam a elaboração de planos de ensino. Prioritariamente na disciplina de Educação Física para a primeira fase do ensino fundamental. Foram muitas inquietações decorrentes da trajetória de estudos e pesquisas proporcionados pelo programa PIBID de Educação Física/UnirG e as regências na Rede Estadual de Ensino, dentre elas, destaca-se as seguintes questões norteadoras: Quais são os limites e possibilidades de inserção das atividades circenses nas aulas de Educação Física nos anos iniciais do ensino fundamental? Qual é a visão dos professores 
sobre as atividades circenses enquanto conteúdo da presente disciplina? Como esse conteúdo tem sido tratado pela proposta curricular do município de Gurupi-TO?

Diante do exposto, acredita-se que as motivações para este estudo, estão relacionadas principalmente ao encontro do circo enquanto conteúdo da proposta curricular, e sua inserção e valorização dentro das aulas de Educação Física à priori nos anos iniciais do ensino fundamental. Acreditamos que seja de suma importância, pois, assim como valorizamos o contexto histórico dos esportes, devemos estudar, entender, e valorizar a origem do circo. Visto ser uma opção de atividade física que proporciona benefícios morfológicos e práticas prazerosas.

Através de análises da proposta curricular utilizada pelas escolas do município, espera-se que o conteúdo relacionado à prática das atividades circenses esteja contemplado e, contudo sejamos capazes de perceber essa prática, diante da visão do profissional de Educação Física. Por meio do discurso do professor, ainda, identificar as possíveis limitações encontradas ao aplicar este conteúdo e as diversas possibilidades de utilização do mesmo no contexto da Educação Física nos anos iniciais do ensino fundamental.

Acredita-se que a limitação a que refere-se o tema em discussão está relacionada inicialmente com a utilização adequada ou adaptada do espaço e materiais necessários para o processo de ensino e aprendizagem do conteúdo circo nos termos mencionados. Concomitantemente, as possibilidades estarão relacionadas com a confecção dos próprios materiais, desenvolver atividades que todos tenham possibilidades e autonomia em executar.

Desta forma este trabalho tem o objetivo principal, verificar os limites e possibilidades de inserção das atividades circenses como conteúdo nas aulas de Educação Física e como esse conteúdo tem sido trabalhado na proposta curricular de Gurupi-TO. E, específicos verificar a possibilidade de inserção do conteúdo circo nas aulas de Educação Física; identificar a visão do profissional de Educação Física sobre o trato do conteúdo circo no documento referência e em suas aulas; analisar o documento referência para a disciplina de Educação Física utilizado pelas escolas municipais; apresentar as possibilidades oferecidas pelo documento referência em relação ao conteúdo circo;

Entendemos que para o profissional de Educação Física este estudo é de grande relevância pois a valorização de uma prática corporal nas escolas proporciona meios de adaptações e o desenvolvimento integral do aluno, o que possibilita novos conhecimentos relacionados às expressões artísticas. O resultado apresentado pode proporcionar aos 
leitores e futuros profissionais uma possibilidade de ampliar os conteúdos da cultura corporal, a fim de alcançar a inovação nas aulas de Educação Física tendo em base uma perspectiva lúdica.

\section{MATERIAIS E METODOS}

Trata-se de uma pesquisa documental e de campo, de natureza qualitativa, com característica exploratória e descritiva. A mesma foi realizada em quatro escolas municipais de Gurupi-TO e com quatro professores graduados em Educação Física (Licenciatura). Para selecionar as referidas escolas optamos por considerar as unidades de ensino que apresentaram um maior número de alunos matriculados no ensino fundamental, como forma de obter resultados mais significativos ao que se refere a visão do professor e desenvolvimento do conteúdo analisado e, disponibilizar de aulas de Educação Física no turno matutino em virtude dos horários disponíveis pelas pesquisadoras para a realização da pesquisa de campo. E a seleção dos sujeitos se deu através dos seguintes critérios: ser professor graduado em Educação Física; atuar nos anos iniciais do ensino fundamental; atuar no turno matutino da referida escola; aceitar participar da pesquisa assinando o Termo de Consentimento Livre e Esclarecido.

O referido estudo foi aprovado pelo Comitê de Ética em Pesquisa com Seres humanos sob o parecer no 2.804.885. Logo em seguida, tratamos de analisar documentos que referenciam os conteúdos curriculares impostos para o ensino público municipal, mais especificamente para a disciplina de Educação Física e coletar os dados por meio de uma entrevista semiestruturada com questões geradoras e auxílio de um aplicativo de gravação de áudio. Para a análise documental, onde foram extraídas informações, construídas etapas e procedimentos para o manuseio com os documentos, além ainda de organizar e tabelar as informações através de categorias e, por fim sintetizar com os dados coletados na entrevista.

A pesquisa apresenta-se um risco mínimo aos participantes em relação ao constrangimento durante a entrevista da pesquisa que foram sanados com a realização da mesma em um lugar reservado. $O$ benefício direto deste estudo para os sujeitos da pesquisa, é que ao final, os professores poderão perceber o quão importante pode ser a inserção das atividades circenses como conteúdo da Educação Física Escolar e ainda, compreender as limitações impostas por documentos e as possibilidades de se trabalhar com o referido conteúdo em suas aulas. 
Para a análise dos resultados foi utilizada a técnica de conteúdo baseada na perspectiva de Moreira, Simões e Porto (2006), os quais a desenvolvem em três fases recomendadas, sendo elas: $1^{\circ}$ Relato ingênuo, $2^{\circ}$ Identificação de atitudes, e $3^{\circ}$ Interpretação. Para a análise de resultados do documento, foi utilizada a técnica de conteúdo baseada na perspectiva de Bardin (2009). Obtendo três fases: $1^{\circ}$ pré-análise, $2^{\circ}$ exploração do material, e $3^{\circ}$ tratamento dos resultados obtidos e interpretação.

\section{RESULTADOS E DISCUSSAOO}

\subsection{ATIVIDADES CIRCENSES NO DOCUMENTO REFERÊNCIA}

Logo a seguir, apresenta-se a tabela com a distribuição de conteúdos de acordo com os eixos supracitados além, ainda de retirar do Documento Referência para a Elaboração de Planos de Ensino do Município de Gurupi-TO (2017) para a disciplina de Educação Física, os conteúdos que integram, de uma forma ou de outra, as atividades circenses. No Ensino Fundamental - Anos Iniciais, são organizados de acordo com série/ano e bimestres subsequentes.

Tabela 1 - Conteúdo Circo no Documento Referência para a Educação Física (2017)

\begin{tabular}{|c|c|c|c|}
\hline Série/Ano & Bimestre & Eixo & Conteúdo \\
\hline $1^{\circ} / 2^{\circ} / 3^{\circ}$ & $1^{\circ}$ & $\begin{array}{l}\text { Atividades rítmicas e } \\
\text { expressivas; }\end{array}$ & $\begin{array}{l}\text { Músicas e atividades que envolvam } \\
\text { as datas comemorativas: carnaval, } \\
\text { Dia do circo - } 15 \text { de março, Páscoa, } \\
\text { Dia do livro - } 18 \text { de abril, Dia do índio - } \\
19 \text { de abril. }\end{array}$ \\
\hline $4^{\circ}$ & $1^{\circ}$ & $\begin{array}{c}\text { Ginástica, jogos, lutas } \\
\text { e esportes. }\end{array}$ & $\begin{array}{c}\text { Corporeidade: o corpo no seu todo e } \\
\text { o movimento consciente. }\end{array}$ \\
\hline $5^{\circ}$ & $1^{\circ}$ & $\begin{array}{c}\text { Ginástica, jogos, lutas } \\
\text { e esportes. }\end{array}$ & $\begin{array}{l}\text { Corporeidade: o corpo no seu todo e } \\
\text { o movimento consciente. } \\
\text { Lateralidade coordenação e equilíbrio } \\
\text { no movimento. }\end{array}$ \\
\hline $1^{\circ} / 2^{\circ} / 3^{\circ} / 4^{\circ} / 5^{\circ}$ & $2^{\circ}$ & $\begin{array}{c}\text { Ginástica, jogos, lutas } \\
\text { e esportes. }\end{array}$ & $\begin{array}{c}\text { Jogos com bolas, arcos, cordas, } \\
\text { bastões, sucatas (pneus, garrafas, } \\
\text { caixas, jornal, latas, etc). }\end{array}$ \\
\hline $1^{\circ} / 2^{\circ} / 3^{\circ} / 4^{\circ} / 5^{\circ}$ & $3^{\circ}$ & $\begin{array}{l}\text { Atividades rítmicas e } \\
\text { expressivas. }\end{array}$ & $\begin{array}{c}\text { Atividades rítmicas e expressivas e } \\
\text { suas manifestações: dança, } \\
\text { brinquedos cantados, instrumentos } \\
\text { musicais. }\end{array}$ \\
\hline $2^{\circ}$ & $4^{\circ}$ & $\begin{array}{l}\text { Ginástica, jogos, lutas } \\
\text { e esportes. }\end{array}$ & $\begin{array}{c}\text { Ginástica olímpica: saltos, } \\
\text { rolamentos para frente e para trás, } \\
\text { avião, roda, vela, Ponte, parada de } \\
\text { dois e três apoios. }\end{array}$ \\
\hline $3^{\circ}$ & $4^{\circ}$ & $\begin{array}{l}\text { Ginástica, jogos, lutas } \\
\text { e esportes. }\end{array}$ & $\begin{array}{l}\text { Ginástica rítmica: saltos, saltos, } \\
\text { Passos, equilíbrios, flexões e giros. }\end{array}$ \\
\hline
\end{tabular}




\begin{tabular}{|c|c|c|c|}
\hline $3^{\circ}$ & $4^{\circ}$ & $\begin{array}{c}\text { Ginástica, jogos, lutas } \\
\text { e esportes. }\end{array}$ & $\begin{array}{l}\text { Movimentos com aparelhos como } \\
\text { cordas, arco e bola: balanceio, } \\
\text { lançamentos, rolamento no solo, } \\
\text { rolamento no corpo, circundação, } \\
\text { rotação, quicar. }\end{array}$ \\
\hline $4^{\circ} / 5^{\circ}$ & $4^{\circ}$ & $\begin{array}{c}\text { Ginástica, jogos, lutas } \\
\text { e esportes. }\end{array}$ & $\begin{array}{l}\text { Ginástica rítmica: saltos, saltitos, } \\
\text { Passos, equilíbrios, flexões e giros } \\
\text { com música. }\end{array}$ \\
\hline $4^{\circ} / 5^{\circ}$ & $4^{\circ}$ & $\begin{array}{c}\text { Ginástica, jogos, lutas } \\
\text { e esportes. }\end{array}$ & $\begin{array}{l}\text { Movimentos com aparelhos como } \\
\text { corda, arco e bola: balanceios, } \\
\text { lançamentos, rolamento no solo, } \\
\text { rolamento no corpo, circundação, } \\
\text { rotação, quicar com música. }\end{array}$ \\
\hline $5^{\circ}$ & $4^{\circ}$ & $\begin{array}{c}\text { Ginástica, jogos, lutas } \\
\text { e esportes. }\end{array}$ & $\begin{array}{l}\text { Ginástica olímpica: preparação } \\
\text { corporal, aquecimento e } \\
\text { alongamento, saltos, rolamento para } \\
\text { frente e para trás, avião, roda, vela, } \\
\text { ponte, parada de dois e três apoios. }\end{array}$ \\
\hline
\end{tabular}

Fonte: Documento Referência para a Elaboração de Planos de Ensino do Município de Gurupi-TO, Ensino Fundamental Anos Iniciais (2017).

Em análise à tabela apresentada, é possível perceber que os conteúdos inseridos no Documento Referência para a Elaboração de Planos de Ensino para a Educação Física do Município de Gurupi-TO, exibem em suas entrelinhas as atividades circenses de formas diversas. Para tanto, apresenta três eixos e diferentes conteúdos que contemplam a ideia de circo na escola, pois as atividades circenses em sua totalidade não se apresentam nesse documento, contudo é possível perceber que se utilizam de atividades que conjecturam com o tema desse estudo.

No entanto, o documento referência apresenta a distribuição dos conteúdos da Educação Física por meio de eixos, sendo eles: Ginástica, jogos, lutas e esportes; Atividades Rítmicas e Expressivas; Conhecimentos sobre o corpo. O circo nas aulas de Educação Física, como se apresenta no documento referência é norteado pelos eixos:

a) Eixo I: Ginástica, jogos, lutas e esportes - apresenta como conteúdos, Corporeidade, Jogos com materiais (corda, arco, bolas, bastões e sucatas), Ginástica Olímpica, Ginástica Rítmica e Movimentos com aparelhos (corda, arco e bolas);

b) Eixo II: Atividades Rítmicas e Expressivas - Músicas e atividades que envolvam datas comemorativas, Atividades rítmicas e expressivas e suas manifestações.

No todo do referido documento ainda se apresenta outro eixo alusivo à disciplina, Conhecimento sobre o corpo, que neste estudo não será utilizado, por não compor o saber circense. 
Diante dos eixos apresentados é perceptível que há uma ligação com as atividades circenses, já que apresenta-se em suas entrelinhas, o movimento em forma de, expressão corporal, e de suas diferentes manifestações onde os conteúdos nos permitem adentrar. $\mathrm{O}$ circo na aula de Educação Física pode ser trabalhado dentro do Eixo I: Ginástica, jogos, lutas e esportes, onde o professor pode aproveitar o máximo do desenvolvimento motor dos seus alunos, além de instigar e explorar seus movimentos corporais. Invernó citado por Doprat e Bortoleto (2007, p. 176) afirma que o circo é:

[...] uma atividade expressiva, que reúne toda uma série de conhecimentos de alto valor educativo, que the dão coerência e justificam sua presença no currículo educativo. Uma atividade que requer uma pedagogia própria, ou ao menos preocupada com suas particularidades.

No tocante, a utilização dos materiais como as bolas (malabares), ajudam a desenvolver coordenação motora, domínio visual, raciocínio logico, entre outros, já as acrobacias possibilitam trabalhar o equilíbrio, flexibilidade, força, altura, etc. que pode entrar nos conteúdos propostos pelo documento referência. Como exemplo, é possível perceber a utilização dos jogos com bolas, arcos, cordas, saltos, que em sua magnitude tratarão, de uma forma ou de outra, de apresentar os fundamentos primeiros referentes às atividades circenses.

Já ao que tange o Eixo II: Atividades Rítmicas e Expressivas, pode-se entender que valoriza-se os movimentos corporais e as expressividades, por meio de manifestações culturais. Cabe ainda, a utilização de músicas para integrar os mesmos e potencializar algumas habilidades como: apreciar as experiências culturais trazidas pelos colegas e reconhecer suas limitações e dificuldades, durante a realização das atividades. Para tanto, é notório que as atividades rítmicas e expressivas concebem um eixo que se apresenta no documento referência e o circo também pode estar intrínseca aos conteúdos, de uma forma ou de outra, podem estar trabalhando os movimentos corporais e suas expressividades em sua totalidade.

\subsection{ATIVIDADES CIRCENSES NO DISCURSO DOS ENTREVISTADOS}

Os profissionais envolvidos nesta amostra são quatro professores graduados no curso de Educação Física - Licenciatura, abordados aqui como P1, P2, P3 e P4. Em 
concordância com a entrevista que foi realizada com os professores da rede municipal de ensino de Gurupi-TO, foram construídas unidades de significados a partir de cada questão geradora, a fim de identificarmos as categorias referentes a cada resposta alcançada. Trataremos aqui de apresentar as unidades de significados e posteriormente discuti-las como categorização para melhor entendimento do leitor.

Tabela 2 - Unidades de significados referentes à questão norteadora 01 - Qual é sua visão sobre a inserção das atividades circenses nas aulas de Educação Física para os anos iniciais do ensino fundamental?

\begin{tabular}{lcccc}
\hline \multicolumn{1}{c}{ UNIDADES DE SINIFICADO } & P1 & P2 & P3 & P4 \\
\hline Álibi educacional & X & & & \\
\hline Vivências lúdicas & X & & & \\
\hline Prazer & X & & & \\
\hline Assimilação de práticas corporais & $\mathrm{X}$ & & & \\
\hline Reconhecer as habilidades & & $\mathrm{X}$ & & \\
\hline Trabalhar o corpo por inteiro & & $\mathrm{X}$ & $\mathrm{X}$ \\
\hline Fundamentos primordiais & & $\mathrm{X}$ & \\
\hline Despertar/desenvolver a motivação & & & $\mathrm{X}$ \\
\hline Coordenação & & & $\mathrm{X}$ \\
\hline Expressividade & & & & $\mathrm{X}$
\end{tabular}

Iniciamos a seguinte discussão apresentando as unidades de significados obtidas por meio das respostas dos professores entrevistados. A primeira refere-se ao Álibi educacional, que pode ser vista e interpretada como uma visão diferente ao que se refere às atividades circenses. O P1 acredita que os profissionais podem "oportunizar a criança a encontrar um álibi educacional, trazendo assim vivências carregadas de ludicidade, prazer e assimilação de práticas corporais vivenciada fora da escola com conteúdos específicos". $\mathrm{E}$, assim já adentramos às outras três unidades de significado, vivências lúdicas, prazer e assimilação de práticas corporais. Em concordância com as palavras do P1, é possível notar que as atividades circenses podem estar inseridas nas aulas de Educação Física, e ainda serem reconhecidas como um conhecimento. Contudo, Claro (2007, p. 102) acreditam que "o objetivo não deve ser formar ou revelar pequenos artistas, assim como não deve ser o objetivo do esporte escolar revelar e treinar atletas".

Em análise às unidades de significado apresentadas na tabela 2, percebe-se que 0 P4, acredita que as atividades circenses são entendidas como conteúdo curricular para o ensino fundamental, havendo várias formas de serem trabalhadas nos anos iniciais. São 
atividades de cunho diferenciado, pois quando aplicadas no âmbito escolar oportuniza a amplitude da expressividade, e ao mesmo tempo desperta e desenvolve a motivação do aluno.

Em concordância com o P4, temos as unidades de significado obtidas a partir da entrevista com P3, este apresenta que essas atividades, na maioria das vezes, são individuais, e capaz de trabalhar o corpo por inteiro. Acredita-se que a partir daí, cada aluno irá apresentar especificamente suas dificuldades. É nesse momento que os mesmos irão reconhecer suas habilidades, contudo, pode-se afirmar que as atividades circenses podem oportunizar a participação de todos no âmbito escolar, independente de suas habilidades e/ou dificuldades, enfim, para o P3 essas atividades podem desenvolver os fundamentos primordiais para o aprimoramento da coordenação, e não somente essa última, mas também todas as habilidades que já foram apresentadas neste, por grande maioria dos entrevistados.

Tabela 3 - Unidades de significados da questão geradora 02 - Você aplica ou já aplicou as atividades circenses como conteúdo em suas aulas de Educação Física para os anos iniciais do ensino fundamental?

\begin{tabular}{lcccc}
\multicolumn{1}{c}{ UNIDADES DE SINIFICADO } & P1 & P2 & P3 & P4 \\
\hline Sim & X & X & X & X \\
\hline Na aula de ginastica. & & $X$ & & \\
\hline Teatro em combinação ao dia do circo. & & & $X$ & \\
\hline Através de jogos de equilíbrio. & & & & \\
\hline
\end{tabular}

É possível perceber que todos os professores já trabalharam atividades circenses em suas aulas, mas como não há uma disciplina específica para tal, os mesmos tentam encaixar o conteúdo da melhor forma possível, para que haja um aprendizado mesmo de maneira superficial, mas de forma significativa. Desta forma o P3 refere-se ao teatro em combinação ao dia do circo, que pode ser vista e interpretada como uma atividade que é trabalhada apenas em datas comemorativas. $O$ teatro pode ser uma forma significativa de se trabalhar a Educação Física como um todo e, de forma superficial pode garantir a aprendizagem sobre o circo, já que o mesmo é amplo quanto à dramaturgia editada para tal. Da mesma maneira, apresentamos as unidades de significados: na aula de ginastica, e através de jogos de equilíbrio. Em concordância com as palavras do P1, P2 e P3 observa-se que os professores em algum momento do ano letivo, proporciona um aprendizado sobre as atividades circenses em suas aulas, assim possibilitando aos alunos conhecimento e valorização de uma manifestação da cultura corporal. 
Contudo, os profissionais que atuam na educação básica, prioritariamente, na primeira fase do ensino fundamental, combinam conteúdos propostos no documento referência para a Educação Física, com o conteúdo circo. É notório, que todos já proporcionaram aos seus alunos, de uma forma ou de outra, algum tipo de experiência.

Tabela 4 - Unidades de significado da questão geradora 03 - Há alguma dificuldade e/ou limitação para a aplicabilidade desse conteúdo em suas aulas? Se sim, quais?

\begin{tabular}{lcccc}
\hline \multicolumn{1}{l}{ UNIDADES DE SINIFICADO } & P1 & P2 & P3 & P4 \\
\hline Sim & & X & X & X \\
\hline Não & X & & & \\
\hline Adaptar, pensar, propor e reutilizar. & X & & & \\
\hline Materiais e espaço. & X & X & & X \\
\hline Criatividade. & & & $X$ &
\end{tabular}

Tabela 5 - Unidades de significado da questão norteadora 04 - Há possibilidade de se trabalhar as atividades circenses como conteúdo em suas aulas? Se sim, como?

\begin{tabular}{lcccc}
\hline \multicolumn{1}{c}{ UNIDADES DE SINIFICADO } & P1 & P2 & P3 & P4 \\
\hline Sim & X & X & X & X \\
\hline Com adaptações. & X & & & \\
\hline Materiais alternativos. & & $\mathrm{X}$ & & \\
\hline Disponibilidade de material. & & $\mathrm{X}$ & & \\
\hline Improvisação & & $\mathrm{X}$ & \\
\hline Criatividade. & & & $\mathrm{X}$ & \\
\hline Aulas extras e planejadas & & & $\mathrm{X}$ & $\mathrm{X}$
\end{tabular}

As tabelas 4 e 5 apresentam, consecutivamente, aos limites e possibilidades de inserção das atividades circenses como conteúdo das aulas de Educação Física, na visão dos profissionais. A primeira unidade de significado apresentada na tabela 4, indica que a maioria dos entrevistados encontram dificuldades na implantação do referido conteúdo. Citam como dificuldade, prioritariamente, os materiais e o espaço, P1, P2 e P4 asseguram encontrar dificuldades, por não haver materiais suficientes e, contudo ter que adaptar atividades com materiais alternativos, além ainda de, não haver espaço suficiente e disponível para a prática de determinadas atividades. P1 também afirma em suas palavras, que é preciso adaptar, pensar, propor e reutilizar. Acredita que "para um nível de vivência e aproximação não se faz necessidade da extensão de uma lona de circo no pátio da escola e muito menos de um picadeiro. Basta adaptar, pensar, propor e reutilizar".

É notório, entretanto que, "[...] não podemos encaminhar no sentido de implantar o "circo na escola", mais sim, devemos pensar na possibilidade de viabilizar o "circo da 
escola" [...] (CLARO, 2007, pg. 103). Em contrapartida o P3, nos apresenta como unidade de significado a criatividade, acredita que a maior dificuldade de inserção de tal conteúdo em seus trabalhos refere-se à falta de criatividade na elaboração de atividades com número mínimo de materiais e espaço disponíveis. No entanto, a limitação se dá por inúmeros motivos, na visão de cada professor, mas prioritariamente a falta de materiais disponíveis.

$\mathrm{Na}$ tabela 5, é possível perceber que os entrevistados concordam que há possibilidade de se trabalhar as atividades circenses como conteúdo nas aulas de Educação Física. No entanto ao analisarmos as respostas dos entrevistados concluímos que tudo depende do local onde o mesmo está inserido, o P4 diz que há possibilidades "desde que seja planejada, com atividades que envolvam toda a turma". As aulas planejadas quando são adaptadas para a realidade de ensino, possibilita o trabalho com criatividade, tanto para o professor, quanto para o aluno, no entanto, os mesmos afirmam que seria melhor e mais fácil de incluir essas atividades em suas aulas, se a escola tivesse maior disponibilidade de material, porém como não há, os professores utilizam da improvisação para proporcionar um conhecimento de qualidade apesar das dificuldades encontradas. Sabendo da importância desse momento na vida das crianças, e por falta de inclusão deste conteúdo na disciplina de Educação Física o P3 sugere que sejam ministradas aulas extras a fim de favorecer o desenvolvimento integral do aluno.

Tabela 6 - Unidades de significado da questão norteadora 05 - Na Proposta Curricular utilizada pela escola, há inserção de atividades circenses como conteúdo? Se sim, como?

\begin{tabular}{lcccc}
\hline \multicolumn{1}{c}{ UNIDADES DE SINIFICADO } & P1 & P2 & P3 & P4 \\
\hline Sim & & X & X & \\
\hline Não & & & & X \\
\hline Em partes & & & & \\
\hline No teatro & & & $X$ & \\
\hline Interdisciplinar & $X$ & & & \\
\hline Plano de curso & $X$ & & & \\
\hline Experiências corporais diferenciadas. & $X$ & & \\
\hline
\end{tabular}

A tabela 6, apresenta que os entrevistados se divergem nas respostas, no que se refere à proposta curricular e a inserção das atividades circenses como conteúdo. Dois deles concordam que esse conteúdo se apresenta na proposta curricular, porém um afirma que não e o P1 diz que em partes, já que o mesmo oferece conteúdos em que as atividades circenses podem estar intrínsecas. Esse último diz que "A proposta curricular do município não existe". Desta maneira é realizado um grupo de estudos com professores da rede 
municipal na tentativa de elaborar o plano de curso para as séries inicias, onde as atividades circenses são inseridas em diferentes disciplinas, e possibilitar o conhecimento em partes, a fim de promover a interdisciplinaridade. Como não há uma disciplina para realização dessas atividades o P3 se refere á aplicação das atividades circenses no teatro, pois ao desenvolver os dois juntos ele tem a oportunidade de explorar as diversidades que esses conteúdos podem proporcionar ao aluno. Atividade circense não está presente como uma disciplina obrigatória, desta forma não é um conteúdo que está sendo trabalhado de maneira contínua, apesar disso os professores tentam inserir em suas aulas a fim de proporcionar um conhecimento que pode ser explorado de diversas formas, e possibilitar experiências corporais diferenciadas, ainda que o mesmo seja pouco trabalhado no âmbito escolar. Em concordância com os relatos dos professores, Claro (2007, pg. 101) propõe que:

[...] a arte circense pode ser um conhecimento a ser ensinado na educação física escolar é, antes de tudo, encará-la como uma manifestação da cultura corporal, uma forma de expressão, possível de ser estudada, aprendida e sistematizada num processo pedagógico. É importante ressaltar esta ideia porque o circo, muitas vezes, pode ser percebido como a exploração dos limites físicos e expressivos do ser humano, um lugar onde pessoas muito especiais realizam feitos praticamente impossíveis.

Por fim, acredita-se que as atividades circenses enquanto conteúdo curricular da Educação Física Escolar não é valorizado nas entrelinhas do Documento Referência, somente apresentado de forma superficial e adaptado aos conteúdos esportivos e de atividades rítmicas e expressivas. Em contrapartida, os entrevistados acreditam que estas atividades podem estar inseridas em suas práticas corporais, mesmo sem estar explícito no documento referência, uma vez que "caracteriza-se como algo diferenciado no âmbito escolar porque amplia conhecimentos que vão além da monocultura esportiva, e que cria mais uma possibilidade aplicada na escola" (CARAMÊS, SILVA e RODRIGUES, 2013, p. 139).

Importante ressaltar que, através da Educação Física, o profissional deve levar para seus alunos atividades que permitam realizar movimentos diversos, e explorar os movimentos corporais, se adequando à faixa etária e ao grau escolar dos alunos, é possibilitar a liberdade de movimentos como: saltar, pular, correr, arremessar, etc. 


\section{CONSIDERAÇOES FINAIS}

Pode-se dizer que os limites para aplicação das atividades circenses estão relacionados às estruturas e a falta de materiais disponíveis nas escolas que os professores trabalham, já as possibilidades estão ligadas no poder adaptar e estimular a criatividade nos alunos, na resolução de problemas, visto que não há a inserção do conteúdo específico. Além disso, os professores acreditam que a melhor forma é, contudo, desenvolver as atividades circenses nos entremeios dos conteúdos, ginástica, teatro e outros pertinentes, isso por ter o conhecimento dos benefícios que essas atividades podem trazer aos alunos em suas aulas de Educação Física na escola, mesmo em realidades distintas.

Em contrapartida, pode-se perceber que essas atividades vêm sendo esquecidas na Educação Física presentada pelo documento que referencia o ensino fundamental - anos iniciais. Notório, em suas entrelinhas, as atividades circenses apenas na comemoração do dia do circo.

Portanto espera-se que esse estudo possa proporcionar uma reflexão aos profissionais e acadêmicos de Educação Física sobre a riqueza de conhecimentos que as atividades circenses podem trazer aos seus alunos, independente de estrutura ou materiais, há possibilidades de se inserir tal conteúdo nas aulas. Por fim, espera-se que os mesmos tenham motivação e incentivo para aplicar este no âmbito escolar.

\section{REFERÉNCIAS}

BALBÉ, G. Pereira. Educação Física escolar: aspectos motivadores. In: EFDeportes.com, Revista Digital. Buenos Aires, Año 13, № 124, Setiembre de 2008.

BARDIN, L. Análise de Conteúdo. Lisboa, Portugal; Edições 70, LDA, 2009.

CARAMÊS, A. S.; SILVA, D. O. Atividades circenses como possibilidade para a Educação Física: Um relato de experiência. In: EFDeportes.com, Revista Digital. Buenos Aires, Año 16, № 161, Octubre de 2011.

CARAMÊS, S. A; KRUG, H. N; et al. Atividades Circenses no âmbito escolar enquanto manifestação de ludicidade e lazer. Motrivivência, n. 39, p. 177-185, Dezembro de 2012.

CLARO, Thiago Sales. Arte circense e educação física: compartilhando uma experiência pedagógica. 2007. 108f. Trabalho de Conclusão de Curso (Graduação)-Faculdade de Educação Física. Universidade Estadual de Campinas, Campinas, 2007.

DUPRAT, Rodrigo Mallet; BORTOLETO, Marco Antonio Coelho. Educação Física escolar: pedagogia e didática das atividades circenses. Revista Brasileira de Ciências do Esporte, v. 28, n. 2, 2007. 
FERRAZ, L. DUARTE, N. M. Atividade circense na Educação Física escolar. In: EFDeportes.com, Revista Digital. Buenos Aires, Año 19, № 202, Marzo de 2015.

FERREIRA, D. C. R; CONCEIÇÃO, W. L. Atividade circense: possibilidades no trato pedagógico na Educação Física. In: EFDeportes.com, Revista Digital. Buenos Aires, Año 18, № 184, Septiembre de 2013.

GONÇALVES, Elisa Pereira. Conversas sobre iniciação à pesquisa científica Campinas, SP: Alínea, 2001.

MARIANO, B. C; CARVALHO, H. M; SOUZA, I. V. O judô como agente educacional e comportamental em crianças de 7 a 12 anos. São Paulo: Lins. 2012. 67p.

MAtTOS, M. G.; ROSSETtO JÚNIOR, A. J.; BLECHER, S. Teoria e Prática da Metodologia da Pesquisa e Educação Física: construindo sua monografia, artigo e projeto de ação. São Paulo: Phorte, 2004.

MOREIRA, W.W.; SIMÕES, R.; PORTO, E. Análise de conteúdo: técnica de elaboração e análise de unidades de significado. R. bras. Ci e Mov. 2005; 13(4): 107-114.

SANTOS, C. C. G., et al. A linguagem corporal circense: interfaces com a educação e a atividade física. São Paulo: Phorte, 2012. 288 p.

SILVA, J. R. S; ALMEIDA, C. D; GUINDANI, J. F. Pesquisa documental: pistas teóricas e metodológicas. In: Revista Brasileira de História \& Ciências Sociais, Ano I, Numero I, Julho de 2009.

SIMON, J. M.; KRONBAUER, G. A. Atividades Circenses: Possibilidades de significação e representação do movimento nas aulas de Educação Física. (Caderno Pedagógico). In: Secretaria do Estado da Educação, PR. Os desafios da escola pública paranaense na perspectiva do professor PDE - Artigos. Volume I, 2013.

VENTURINI, G. R. O, et al. Atividades circenses nas aulas de Educação Física. In: EFDeportes.com, Revista Digital. Buenos Aires, Año 15, № 146, Julio de 2010.

VENDRUSCOLO, Pereira; RAMOS, Cinthia. O circo na escola. Motriz: Revista de Educação Física, p. 729-737, 2009. 